\title{
La estela CG 20517 del rey Senaaib: un estudio de los problemas para su interpretación
}

\section{Leila Salem*}

\section{Resumen}

El presente artículo consiste en la primera publicación completa y detallada de la estela del rey Senaaib, estela de adoración al dios Min-Horus-nakht (CG20517) encontrada en Abidos y que actualmente es custodiada por el Museo de Antigüedades Egipcias de El Cairo. Proponemos una discusión acerca de la posible datación de la estela y la ubicación del faraón dentro de la cronología dinástica del antiguo Egipto. A su vez, realizaremos la transliteración y traducción completa de sus textos -primera versión en lengua española-, y una descripción y análisis detallado de su iconografía y de los problemas derivados de las inscripciones y traducción de sus textos. Además incluiremos diferentes debates y argumentos, muchos de ellos contradictorios, planteados por los especialistas para interpretar la estela, proponiendo nuevos interrogantes a partir de una mirada interpretativa integradora de las perspectivas de análisis.

\section{King Senaaib's CG 20517 stela: a study of the problems for its interpretation}

\begin{abstract}
This article presents the first complete and detailed published data about the King Senaaib stela, which is a worship stela for god Min-Horus-nakht (GC 20517). It was found in Abydos and is currently being guarded by the Egyptian Museum of Antiquities in Cairo. We propose a discussion about the possible dating of the stela and the location of the pharaoh within the ancient Egyptian dynastic chronology. At the same time, we will make a transliteration and complete translation of the texts - the first version in Spanish-. We will finally present a description and detailed analysis of its iconography and the problems derived from their inscriptions and translation. We will also include different debates and arguments stated by specialists when interpreting the stela, many of them contradictory, and we will propose new questions arising from an integrated view of different analytic perspectives.
\end{abstract}

Recibido:

29 de abril de 2019

Aceptado:

10 de diciembre de 2019

\section{Palabras clave}

Estela CG 20517

Senaaib

Abidos

Min-Horus-nakht

Segundo Período Intermedio

\section{Keywords}

Stela CG20517

Senaaib

Abydos

Min-Horus-nakht

Second Intermediate Period

* Centro de Estudios de Sociedades Precapitalistas, Instituto de Investigaciones en Humanidades y Ciencias Sociales (IdIHCS), Facultad de Humanidades y Ciencias de la Educación, Universidad Nacional de La Plata (UNLP) - CONICET. Calle 51, entre 124 y 125 (CP 1925) Ensenada, Buenos Aires, Argentina. E-mal: leilasalemunlp@gmail.com 


\title{
Introducción: la estela CG 20517 en el contexto religioso de Abidos
}

\author{
"Each stela its offers if we are ready to ask the right \\ questions. It is challenge for us to spot and decipher these \\ answers and understand the petrified cultural codes"
}

Detlef Franke

1. 'Umm el- Qaab fue excavado desde fines del siglo XIX primero por Émile Amélineau y luego por William Matthew Flinders enza con sus trabajos Günter Dreyer, quien ha realizado numerosas publicaciones; sólo por citar algunas de importancia: Dreyer, 1990; 1998; Dreyer et al., 2006. Para una historia de los trabajos excavación y un conocimiento Simpson (1974); O'Connor (2009); Richards (2005).

2. Lavier (1989, p.5) propuso a pqr como el centro de la celebración,quizá 'Umm el-Qa'ab

(Schäffer, 1904). Leahy (1989) asegura que en la dinastía

XIII ‘Umm el-Qa'ab se había establecido como el lugar de entierro de Osiris. Algunos trabajos

de referencia son: Lavier (1989);

O'Connor (2009); Simpson (1974);

Snape (2011) y Smith (2017).

3. En relación a la reconstrucción de la celebración de los Misterios de Osiris, véase: Lavier (1989); Leahy (1989); Rosell (2018); Smith (2017).
Entre los años 1858 y 1861 el egiptólogo francés Auguste Mariette supervisó los trabajos de excavación en Abidos (Mariette, 1880), sitio que se encuentra al sur de Egipto, aproximadamente a unos $91 \mathrm{~km}$ al noroeste de Tebas. Con Mariette se inicia un largo recorrido de trabajos arqueológicos y de estudios históricos de uno de los principales centros de culto del antiguo Egipto, específicamente alrededor de la figura del dios Osiris.

Abidos, uno de los primeros conjuntos urbanos del Alto Egipto durante el periodo de Nagada II c-d (3600-3300 a.C.), registra un nivel de ocupación de su necrópolis durante todo el IV milenio. Es allí donde se pasa sin interrupciones de las tumbas de las elites locales predinásticas a los enterramientos de los faraones de las dinastías I y II de un Egipto ya unificado cultural y territorialmente (Cervelló Autuori, 2009). En el cementerio de 'Umm el-Qa'ab se reconocen los nombres de los primeros reyes de Egipto (Seidlmayer, 2007) ${ }^{1}$, entre ellos el segundo o el tercer faraón de la dinastía I, Djer (Leprohon, 2013). Durante la dinastía XII (1939-1760 a.C.), probablemente fue su tumba la que se identificó con el lugar de enterramiento de Osiris (Lavier, 1989; Leahy, 1989 $)^{2}$ haciendo de Abidos uno de los principales centros religiosos de Egipto.

Durante el Reino Medio (1980-1760 a.C.), Abidos se configuró como un sitio de peregrinación nacional (O’Connor, 2009; Yoyotte, 1960). A lo largo de una ruta procesional - la terraza del Gran Dios, $r w d$ ntr ${ }^{\complement} 3$ (Simpson, 1974; Yamamoto, 2015a) - que unía las zonas de cultivo con las tumbas reales (donde estaba enterrado Osiris), se realizaban festividades que recrearon ritualmente la muerte y el renacimiento del dios. Durante la celebración de los Misterios de Osiris ${ }^{3}$ reyes e individuos de la elite egipcia (muchas veces con su grupo familiar) dejaron constancia de su participación por medio del levantamiento de estelas. Las estelas eran colocadas a lo largo del camino, en algunos casos dentro de capillas de ofrendas — capillas mahat (maHat) (Simpson, 1974; Snape, 2011; Yamamoto, 2015b)—, junto con estatuas y mesas de ofrendas.

El propósito de las estelas abideanas era lograr la identificación del o de los individuos a quienes estaban dedicadas, con el dios Osiris (Lavier, 1989). Por un lado, funcionaban como una marca de la presencia del propietario de la estela (y posiblemente su familia) en la peregrinación a Abidos (Snape, 2011); es decir, las estelas recordaban la participación durante los Misterios y por ello recibirían eternamente los beneficios de la celebración (Lavier, 1989). Por otro lado, las estelas eran un ex-voto, esto es, una ofrenda en busca de la asociación eterna con el dios Osiris (Simpson, 1974), que garantizaría su acceso al Más Allá.

En el presente trabajo nos proponemos dar a conocer en forma completa una de las cientos de estelas encontradas por los trabajos de excavación coordinados por Mariette en la necrópolis en Abidos (Mariette, 1888): la estela del rey Senaaib Menkhawra (Figura 1). El nombre de nacimiento del faraón Senaaib ( $\left.s n^{c \subset} i b\right)$ fue un nombre personal muy común durante el Segundo Periodo Intermedio (Beckerath, 1964).

Esta estela fue hallada en el perímetro norte del área de la necrópolis conocida como Kom es- Sultan. Este recinto cultual y funerario posiblemente construido durante el reinado de Djer (Van Wetering, 2004), que estaba conectado ritualmente con el cementerio predinástico y dinástico de 'Umm el-Qa'ab, fue el área principal donde se concentraron los trabajos de excavación coordinados por Mariette. Las estelas y 


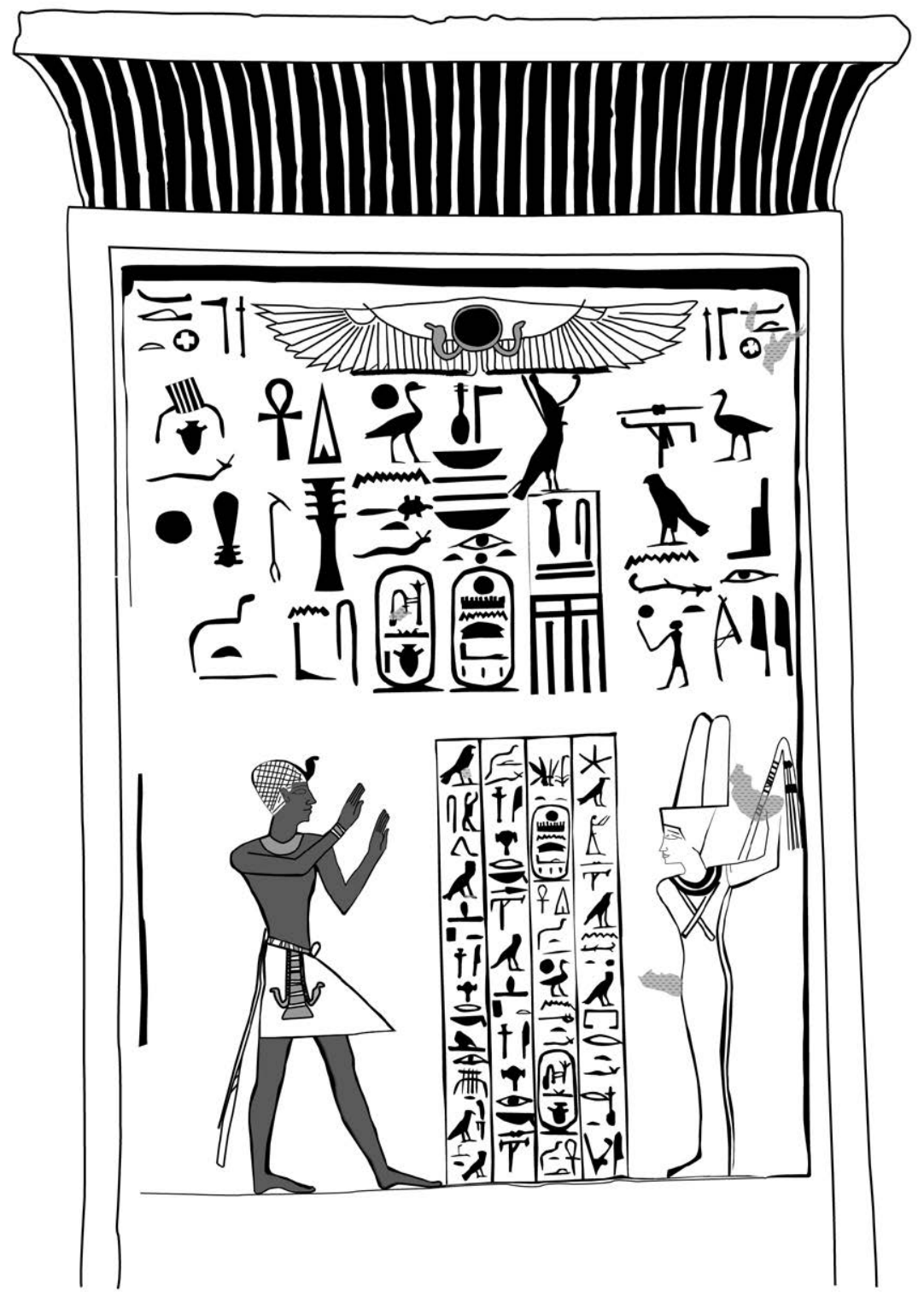

Figura 1. Calco digital de la estela CG 20517.

otros objetos allí encontrados fueron enviados para su resguardo al Museo del Boulaq, institución dirigida y creada por el propio Mariette en 1858 (Lebée, 2013; Leclant, 1981; Reid, 2002). Los acervos del Museo del Boulaq pasaron al Museo de Antigüedades Egipcias de El Cairo en 1902, momento cuando las estelas halladas en el sitio de Abidos adquieren su nueva nomenclatura (CG) y en el caso de la estela de Senaaib la nueva catalogación la numera como CG20517 (Figura 1).

Si bien la estela del rey Senaaib es referenciada en los catálogos de monumentos de Abidos y ha sido estudiada o mencionada por diferentes investigadores en relación con algunos problemas históricos y epigráficos específicos que resultan de la misma, no se ha publicado hasta el momento un trabajo que la analice desde una perspectiva integradora de todos ellos. Es por este motivo que planteamos un estudio sistemático de la misma que integre las diferentes problemáticas, poniendo en consideración no sólo las que surgen del texto y/o la titulatura del rey, sino también aquellas relacionadas a su funcionalidad y espacialidad derivadas de su materialidad. 
En los dos primeros apartados se realiza un recorrido por las especificaciones realizadas por los catálogos de piezas egipcias que la han publicado previamente, con el fin de dar a conocer el estado en el momento de su hallazgo y poder establecer una comparación con su condición actual. En el tercero se tratará la problemática en torno a la figura del rey Senaaib, especialmente la dificultad de su datación y ubicación certera en la línea dinástica y se expondrán los diferentes argumentos que han sido esgrimidos a favor o en contra de la datación de la estela en alguna dinastía del Segundo Periodo Intermedio. Por otra parte, la representación del rey Senaaib con la corona khepresh será analizada en el siguiente apartado, lo que permitirá comprender potenciales funcionalidades de su representación en la estela. Luego nos concentraremos en la figura del dios Min- Horus-nakht y su himno de adoración, para el análisis de la legitimidad monárquica en el contexto cultual abideano. Por último, se propone la transliteración y traducción de los textos, la primera en lengua española, dando cuenta de algunos de los problemas derivados de la misma.

\section{La estela de Senaaib Menkhaura, CG 20517}

Los trabajos conducidos por Mariette en Abidos entre 1858 y 1861 se concentraron en el área del cementerio norte, si bien se sabe no estuvo presente en el sitio (Simpson, 1974). Estos trabajos arrojaron como resultado el hallazgo de más de 800 estelas (Mariette, 1880). En Catalogue général des monumentsd'Abydos (1880), Mariette realiza un inventario de todos los objetos descubiertos en la necrópolis. El catálogo enumera estatuas - de divinidades, de particulares y funerarias-, mesas de ofrendas, sarcófagos y momias, escarabajos, amuletos y emblemas, naos, piramidiones, jarrones y otros monumentos. Las estelas — definidas por Mariette (1880) como losas planas de madera o piedra (principalmente caliza o granito) que se utilizaron en el antiguo Egipto para escribir textos- ocupan un lugar destacado en su publicación, posición de privilegio que aún conservan entre los especialistas. De hecho, en la actualidad las estelas de Abidos son consideradas una fuente primordial para la comprensión de la sociedad, las elites locales y las creencias religiosas, especialmente del Reino Medio y Nuevo Reino (Grajetzki, 2006; Richards, 2005).

Las estelas recuperadas en Abidos fueron datadas por Mariette entre la dinastía VI y la Baja Época, destacándose en calidad y cantidad aquellas correspondientes a las dinastías XII y XIII. A su vez indica entre las pertenecientes a las dinastías XIII a XIV la número 771, numeración que corresponde a la estela del rey Senaaib. En el catálogo realizado por Mariette hace una descripción general de la misma (medidas, material, colores, etc.), se indican los textos jeroglíficos de la titulatura del rey y se traducen parcialmente en francés (sin transcribir ningún signo jeroglífico ni detallar la transliteración de los mismos), solamente las dos últimas líneas del texto que corresponden al himno de adoración al dios Min.

En relación con la ubicación de la estela en el momento de ser encontrada, Mariette (1880) únicamente indica que fue hallada en el recinto norte de Kom es-Sultan. Como advierte O'Connor (2009, p. 26), Mariette omite información estratigráfica, además de indicaciones sobre la ubicación exacta y correlación con otras estelas y objetos, por lo que se pierde una información sustancial para la investigación actual. La falta de atención por parte de los arqueólogos del contexto de hallazgo es un problema que puede extenderse a la mayoría de las estelas encontradas en Abidos. De todos modos, se sabe que la mayoría de éstas podían apoyarse contra la pared exterior del templo, que había estelas independientes dentro y fuera de algún edificio, otras en las tumbas reales y/o estructuras mortuorias y que había pequeñas capillas (mahat) que contenían una o más estelas (Gehrden, 1986).

Para Mariette la estela de Senaaib Menkhawra - a quien denomina como Nââhetes de un estilo "mediocre", con signos jeroglíficos uniformemente pintados en verde 
claro, lo que puede observarse en la reproducción fotográfica que hace de la misma. Además, al considerarla un modelo representativo de las estelas de la dinastía XIV, la pone en correlación con un conjunto de estelas, agrupándolas por categorías según sus características ${ }^{4}$.

Por otro lado, en los cuatro volúmenes de la obra Grab-und Denksteine des Mittleren Reichs im Museum von Kairo, Lange y Schäfer (1902-1925) completan y amplían la información de las estelas publicada por Mariette en 1880. Así, se presenta una nueva catalogación y la número 771 adquiere su denominación actual, CG 20517.

Para la estela de Senaaib, Lange y Schäfer dan a conocer completos sus textos jeroglíficos, pero no proponen una transliteración y traducción para los mismos. La escritura jeroglífica corresponde a la numeración a, b y e del esquema de lectura propuesto por los autores. Se describen con detalle los colores verdes, rojos y azules que predominan tanto en la escritura, como en los contornos que delimitan su forma rectangular. Es decir, prevalece el color verde en los signos de la escritura jeroglífica, mientras que los tonos ocres y amarillos priman en la figura humana del rey (Lange y Schäfer, 1902-1925). También dan cuenta de las profundidades de los surcos en el grabado de los signos y, como ya lo había apreciado Mariette (1880), los describen como flacos y sin demasiada profundidad, aumentado su calado en las líneas jeroglíficas que corresponden al himno de adoración al dios Min. En el punto c detallan la representación del faraón con un dibujo del cintillo que lleva sobre su faldellín y describen la representación del dios Min con un dibujo de su corona, que corresponde al punto d del esquema. La estela CG 20517 no ha sido fotografiada para esta publicación.

\section{Descripción del estado actual de la estela CG20517}

Esta estela es, en sí misma, una falsa puerta rectangular de piedra caliza. De gran tamaño, tiene una altura de 0,98 $\mathrm{m}$ y un ancho de $0,60 \mathrm{~m}$. Los investigadores coinciden en describirla como una estela de estilo mediocre y de mala calidad en sus terminaciones (Mariette, 1880; Ryholt, 1997). El dintel, que hace de marco rectangular definiendo su contorno, se decora con líneas rectas verticales que intercalan los colores rojo/ocre, verde y azul; en tanto el recuadro principal se compone de tres registros, que hemos secuenciado con una letra, según se observa en el esquema (Figura 2).

A. En el centro del primer registro se representa el disco solar que preserva intacto un rojo intenso, mientras que la línea que lo bordea $-\mathrm{y}$ de la cual se dibujan a cada lado cobras - está coloreado en amarillo. Las alas apenas conservan su tono verdeazulado original. En cada uno de los extremos se duplica la misma secuencia de signos jeroglíficos (BHdty $n \operatorname{Tr} a A$ ), siendo los del lado derecho los mayormente dañados.

B. Se compone de ocho columnas de escritura jeroglífica con surcos no muy profundos, pero bien definidos, coloreados de verde. Para seis de las columnas sigue un sentido de escritura de derecha a izquierda y dentro del texto se presentan los títulos del rey Senaaib, para quien está realizada la pieza; por su parte, los signos que están a la derecha y arriba de Min están escritos y se leen de izquierda a derecha colocados en dos columnas.

C. En el tercer registro se encuentran las representaciones del faraón Senaaib a la izquierda y de Min a la derecha del recuadro de cuatro columnas donde se escribe el himno dedicado en honor al dios. El rey, con su cuerpo pintado de un fuerte color ocre, alza los brazos en gesto de alabanza. Senaaib lleva un collar y un feldallín, además de la corona khepresh en su cabeza. En tanto, e, el dios Min está
4. Una primera categoría considera veinte estelas, dos son de adoración Min: CG 20188, CG20612. La segunda compuesta por diez estelas de las que tiene en cuenta aquellas con una singular representación de las cabezas de los individuos. En la última, siete estelas tienen un mismo estilo de jeroglíficos, una la estela de adoración a Min CG2O24O. 


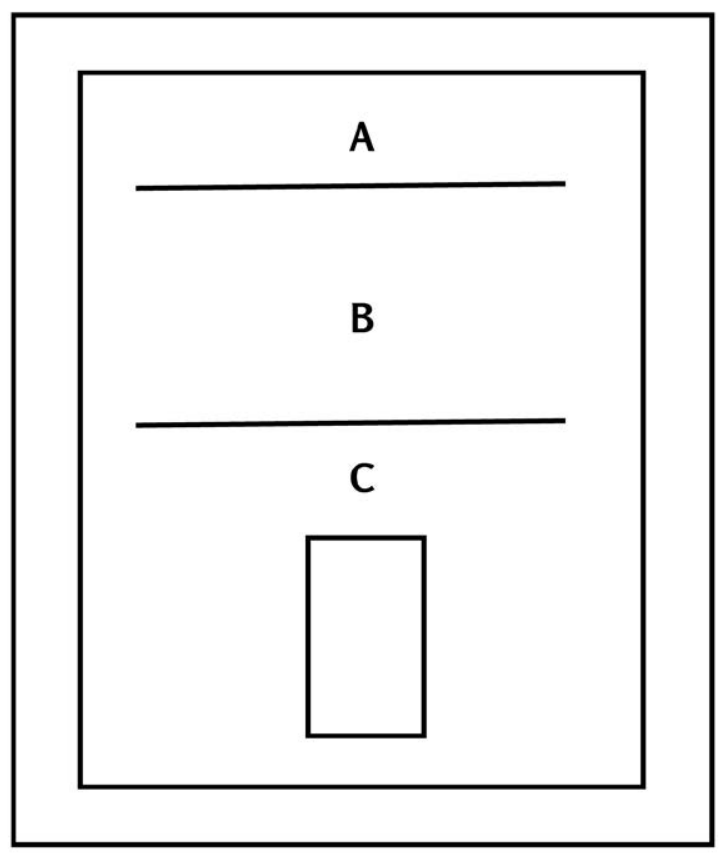

Figura 2. Esquema de la estela CG 20517.

amortajado, porta la corona de dos plumas y sostiene con su brazo levantado en alto el flagelo. La proporción de las figuras le da una mayor preponderancia al rey, aunque sólo por tener mayor altura. Los trazos de la figura humana y del dios Min son simples, con líneas bien definidas y sin lograr gran calidad estilística en toda la composición de la estela. La confección simple de los signos de escritura para las secciones B y C hace que predomine en la estela una composición clara y sin mayores dificultades para la comprensión y lectura de los signos jeroglíficos.

En una caracterización y definición amplia realizada por Gehrden (1986) para las estelas conmemorativas del Reino Medio al Segundo Periodo Intermedio dedicadas a individuos - ya sea dioses o particulares - se propone como regla general la siguiente tipificación: 1. poseen una forma con el borde superior redondeado y el texto principal en la parte superior (particularmente los títulos y el nombre del individuo en cuestión), es decir lo que corresponde a nuestra sección B; 2 . un texto en la parte inferior de la estela, desde himnos u oraciones para los dioses, hasta información autobiográfica, genealógica o fórmulas de ofrenda, que se corresponde con nuestra sección C. 3 . diferentes tipos de representaciones como puede ser un hombre sentado frente a una mesa de ofrendas, de pie u orando, como así también sus parientes, conocidos o dioses, lo que también corresponde a la sección C; 4 . por último, el borde superior se caracteriza por la representación principalmente de un par de ojos udjat o un disco solar alado, es decir lo que indicamos como sección A. Por lo tanto, la disposición y tipos de textos, los símbolos y las figuras humanas de la estela CG 20517 se encuentran dentro de los parámetros esperables para las estelas del Reino Medio al Segundo Periodo Intermedio.

\section{El rey Senaaib y los problemas de datación de su reinado}

La estela CG20517 es el único monumento conocido hasta el momento que registra para la historia faraónica el nombre completo del faraón Senaaib. En la estela CG 20517 se detallan los tres nombres del rey:

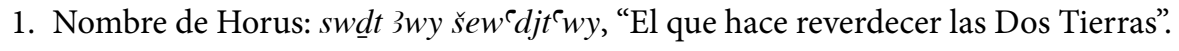


2. Nombre del trono: $M n h h^{\top} . w R^{\top}$ Menkhawra, "Estables son las apariciones de Ra”.

3. Nombre de nacimiento: $s n^{\Subset} i b$ Senaaib, "Suave de corazón”.

Cuando Mariette publica por primera vez la estela propone que su propietario sería un rey de la dinastía XIV (Tabla 1), de acuerdo con el lugar que su nombre ocupa en la Lista Real de Turín, (papiro Turín 1874 verso) ${ }^{5}$. Al respecto hay que tener en cuenta que para la reconstrucción de la cronología faraónica, tanto la lista de Abidos como la de Saqqara como otras listas de reyes omiten la mención de los faraones desde finales de la dinastía XII hasta comienzos de la dinastía XVIII. Por esta razón la información que el papiro de Turín brinda acerca de esta cronología adquiere un valor excepcional (Farina, 1938).

Marritte considera que si la datación en la dinastía XIV podría probarse fehacientemente, es sustancial el aporte de la estela al conocimiento de la historia faraónica, especialmente si se consideran dos cuestiones. En primer lugar, se deduce de la cronología propuesta por Manetón, la dinastía XIV proviene de Cois y las dinastías XV, XVI y XVII son las de los reyes- pastores $^{6}$. En palabras de Manetón (según Africano):

“La dinastía XIV contó con 16 reyes de Cois, que imperaron 184 años. La dinastía $\mathrm{XV}$ se componía de reyes-pastores y fueron seis reyes de procedencia fenicia; se apoderaron de Menfis y fundaron una ciudad en el nomo de Setroite, que sirvió de base para someter a los egipcios. Saítas, el primer rey, gobernó 19 años, y él derivó en nomo saíta..." (tomado de Jiménez Hernández y Jiménez Serrano, 2008, p. 113 y p. 118).

Con anterioridad Mariette había defendido la idea de que la dinastía XIII y XIV habían sido contemporáneas; el descubrimiento de la estela de Senaaib permitía entonces preguntarse sobre la existencia de una dinastía fuerte en la ciudad de Cois hasta el punto de poder llegar a rivalizar con faraones como Sobekhotep y Neferhotep. Uno de los problemas de esta interpretación sugerida por Mariette es que ambas dinastías rivales habrían ocupado un mismo cementerio, por lo que concluyó que sería mucho más probable que la dinastía XIV haya sucedido a la XIII.

En segundo lugar, Mariette plantea la reducción del tiempo transcurrido entre el final de la dinastía XII y la invasión de los hicsos, sugiriendo que este hecho central en la historia egipcia tuvo lugar al comienzo de la dinastía XIV y no a comienzos de la dinastía XV, como lo indica Manetón. Por esta razón, la estela de Senaaib prueba que durante la dinastía XIV los pastores aún no estaban en Egipto, o al menos todavía no se habían instalado en Abidos. La verdadera importancia de la estela radica para Mariette en ser, quizá, una fuente única de un faraón de la dinastía XIV, periodo tan pobremente conocido en ese entonces (Mariette, 1880; Waddell, 1940). Esta estela le permitió sostener que la dinastía XIV había sucedido a la dinastía XIII y que al menos en sus orígenes aún no se había producido la invasión de los hicsos.

Sin embargo, sigue siendo de dudosa lectura el nombre de Senaaib en la Lista Real de Turín y se pone en discusión la posible datación y ubicación del rey dentro de la cronología dinástica del Egipto faraónico. La Lista Real de Turín es un documento muy complejo que debe ser tratado con precaución (Ryholt, 2004, 2006), ya que, entre algunos motivos, su estado actual de deterioro no permite una lectura clara de los nombres de algunos faraones; además, aún no se han determinado la ubicación de todos los fragmentos para la reconstrucción de las columnas y la correcta ubicación de los nombres de los gobernantes dentro de una dinastía.

Meyer en Aegyptische Chronologie (1904), proporciona las ideas modernas para la datación absoluta, a partir de la combinación de cálculos astronómicos (la aparición

5. Sobre el Canon de Turín véase, Meyer (1904); Farina (1938); Gardiner (1959); Malek (1982); Redford (1986); Ryholt (1997, 2004, 2006); Beckerath (1964).

6. En relación a la cronología de Manetón, especialmente para la organización de la sucesión dinástica durante el Segundo Periodo Intermedio véase: Helck (1956); Jiménez Hernández y Jiménez Serrano (2008); Beckerath (1964). 


\begin{tabular}{|l|l|}
\hline Datación posible de la estela CG 20517 & Referencias bibliográficas \\
\hline Tardía Dinastía XIII & Beckerath (1964) \\
& Davies (1982) \\
Ertman (1976) \\
Dinastía XIV & Mariette (1880) \\
Farina (1938) \\
Dinastía de Abidos & Ryholt (1997) \\
Tardía dinastía XVI / temprana dinastía XVII & Siesse (2015) \\
\hline
\end{tabular}

Tabla 1. Diferencias en la datación del reinado del rey Senaaib.

de la estrella Sirio coincide con el inicio del calendario y la inundación de las aguas del Nilo), el análisis de textos egipcios (como el papiro de la Lista Real de Turín o el papiro Ebers), la crítica a las fuentes clásicas (como Heródoto o Manetón) e información arqueológica. Para la Lista Real de Turín considera para la columna VII 27 líneas, tres perdidas; para la columna VIII 24 líneas, siete perdidas; y para la columna IX, 27 líneas, cuatro perdidas. Con respecto a la columna X contenía originalmente un total de 32 líneas, pero no todas ellas señalaban nombres reales, sino también información de carácter general y es en esta columna donde ubica con toda probabilidad a los Hicsos y el nombre de Apofis, por lo que correspondería a la columna IX de Farina (1938) y Gardiner (1959) que dan para la Lista de Turín, mientras que los nombres restantes pertenecerían a los reyes de las dinastías XIII y XIV (Meyer, 1904), es decir donde Mariette originariamente ubicó al rey Senaaib (Tabla 1).

De todos modos, Meyer (1904) no realiza ningún tipo de transcripción y traducción de los nombres propios de los reyes de estas dinastías. De hecho Farina en Il papiro dei $R e$ (1938) es quien realiza uno de los primeros trabajos sistemáticos al respecto. En su libro, este autor realiza una transcripción del hierático al jeroglífico y traduce al italiano el nombre de cada uno de los gobernantes egipcios siguiendo el trabajo de ordenamiento de columnas y fragmentos realizados en una versión facsimilar por Gustav Seyfarth.

En el apartado sobre las dinastías XII y XIV es donde deberíamos encontrar la mención a Senaaib si seguimos las sugerencias de Mariette. Del mismo modo que éste, Farina - ambos siguiendo las ideas de Manetón y Africano- acuerdan con la idea de situar a la dinastía XIV como originaria de la ciudad de Cois. Pero, según una reinterpretación a través de la Lista de Turín, se modifica de la clásica representación griega de un total de 76 gobernantes. Para Farina los faraones de la dinastía XIV serían un total de 72: 16 faraones de la columna VIII de la línea cuatro a la línea 19; 30 de la línea 20 de la columna VIII hasta la línea 19 de la columna IX; y 26 de la línea 20 de la columna IX hasta la línea 13 de la columna X (Farina, 1938) (Tabla 1).

Farina indica en la columna IX línea ocho el siguiente título para un rey: Mennofrūrîe. El signo final de su trazo que quedan en la fuente original (Farina, 1938). Entonces, si seguimos la lectura de Farina, Senaaib pierde su lugar como faraón de la dinastía XIV en la Lista Real de Turín. Para otras dinastías, no se ha preservado ningún nombre real que pueda coincidir con el de Senaaib.

En la transcripción realizada por Gardiner en The Royal Canon of Turin (1956) y reproducida por Kitchen (1999), se lee en el fragmento 108 en el verso del papiro, columna IX línea ocho: ilegible, cualquier tipo de lectura del signo que allí se encuentra quedaría en el plano de la especulación. 
Por otra parte Malek (1982), quien reconstruye la versión original de la cual el escriba de la Lista Real de Turín copia los nombres de los reyes, sitúa a Men[...]ra en la columna XVI, línea cuatro, ubicación que correspondería también a los faraones de la dinastía XIV. Es decir, sólo se produce un reordenamiento de las líneas y estructura del papiro, no así de la posible datación del rey Senaaib en la dinastía XIV. Todo esto, si se acepta

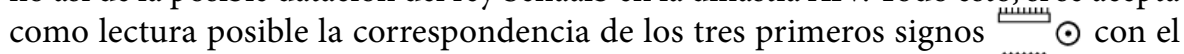
nombre del trono de Senaaib según se registra en la estela CG 20517. Sin embargo, al no estar completo no puede asegurarse fehacientemente que sea el mismo rey. Aun cuando, seguramente este fue el nombre que leyó Mariette para ubicar al faraón Senaaib como un gobernante de la dinastía XIV, las actuales interpretaciones del papiro permiten afirmar una lectura errónea por parte del investigador; por ende pierde sentido la idea de que Senaaib haya sido uno de los dieciséis reyes de la dinastía XIV proveniente de Cois. Además el contexto cultural y religioso de las festividades osiríacas en Abidos y la figuración del dios Min-Horus-nakht como una de las más importantes divinidades abideanas durante el Segundo Periodo Intermedio, coloca a la estela de Senaaib por fuera de la región del Delta a la que perteneció la dinastía XIV.

Beckerath (1964) es quien realiza uno de los primeros y más importantes estudios en profundidad sobre el Segundo Periodo Intermedio y una propuesta de la cronología faraónica. El autor advierte que el reinado de Senaaib no es fácil de clasificar y sugiere para la dinastía XIII una línea sucesoria en la cual éste se posiciona como uno de los herederos del faraón Menkhawra Sobekhotep VII, probablemente entre los reinados de Neferhotep III y Wepwawemsaf (Tabla 1).

Ryholt (1997) propone algunas correcciones al orden dado por Malek para los reyes de la dinastía XIV (Tabla 1). Efectivamente, en The Political Situation (1997), plantea la existencia de una dinastía local en Abidos (Tinis), idea que ya había sido sugerida por Dtelef Franke en el año 1988. La breve dinastía de Abidos habría sido contemporánea a la dinastía XVI de Tebas (que coincide con la tradicional dinastía XVII), o al menos inmediatamente posterior (Ryholt, 1997). Es decir, que su existencia se habría dado en el lapso temporal entre la caída de la dinastía XIII a raíz de la conquista de los hicsos de la capital menfita y el avance de éstos hacia Tebas en el sur de Egipto.

Los reyes que componen la dinastía de Abidos son tres: Wepwawemsaf Sekhemreneferkhaw, Pantjeny Sekhemrekhutawy y Senaaib Menkhawra cuyos nombres ${ }^{7}$, afirma Ryholt, no se registran en la Lista Real de Turín, es decir que asume la postura ya marcada por Farina que en el papiro no figura ningún rey con ese nombre. Sin embargo, dice Ryholt, sí se preserva en monumentos de Abidos, como por ejemplo: las estelas reales BM EA 969, BM EA 630 y CG 20517 respectivamente, todas ellas con la característica en común de estar realizadas en muy mala calidad. Además, para el segundo de los reyes la composición de los nombres se conectan directamente con el nomo tinita al estar el nombre teofórico compuesto por $p 3-n$-tnny- "El de Tinis", expresando una filiación directa con la ciudad de origen de esta dinastía. Por otro lado, los tres gobernantes son conocidos por estelas votivas halladas en Abidos. De todos modos, la calidad de manufactura de las estelas no debería ser el único factor aglutinante entre ellas, por ejemplo los análisis sobre la materialidad de los objetos (Salem y Calomino, en prensa) habilitan a nuevas preguntas respecto de la distribución espacial y temporal, las prácticas concretas vinculadas y la relación entre la escritura y el objeto, análisis que permitirán reforzar o descartar este argumento.

También Ryholt (1997) realiza algunas inducciones indirectas para proponer la existencia de la dinastía de Abidos para el Segundo Periodo Intermedio en Egipto (Tabla 1). Por un lado, cuando la dinastía XV (Hicsos) conquistó la ciudad capital de Menfis poniendo fin a la dinastía XIII, fue la dinastía XVI tebana la que se formó para rivalizar con los reyes extranjeros. Ninguna de las dos logró un alcance político hasta
7. Se ha propuesto nueva evidencia a favor de la dinastía de Abidos a partir del descubrimiento en el año 2014 de la tumba del faraón Senebkay (Wegner, 2015). 
la ciudad de Abidos, por lo que puede suponerse la formación de una dinastía local que respetase su poder político en la región, constituyéndose en una organización dinástica del mismo modo que lo habían realizado los reyes tebanos (dinastía XVI). Por otro lado, la existencia de una dinastía de Abidos durante el Segundo Periodo Intermedio podría explicar la presencia de un grupo de reyes efímeros después de la dinastía XVI en la Lista Real de Turín. Esto tiene sentido para Ryholt, ya que en la citada Lista los nombres de los reyes se colocan uno detrás del otro, sin indicarse dinastías contemporáneas, por lo que justifica que hayan sido simultáneos a la dinastía XVI o inmediatamente posteriores.

Siguiendo el razonamiento manifestado por Ryholt (1997), deberíamos preguntarnos acerca de la relación que Senaaib pudo haber tenido con Wepwawetemsaf y Pantjeny, más allá de la idea que sus estelas fueron encontradas en Abidos, cuando se sabe que los contextos de hallazgo se han perdido y por ende toda posibilidad de análisis mediante una conexión de este tipo. De hecho, Marcel Marée (2010) proporciona evidencia contraria a la existencia de una dinastía de Abidos. En "A Sculpture Workshop at Abydos from the late Sixteenth or Early Seventeenth Dynasty", propone que en Abidos, para la tardía dinastía XVI o una temprana dinasta XVII, existió un taller de escultores dedicados a la producción de estelas reales, algunas de las cuales fueron depositadas en el sitio. Por un lado, el taller tuvo a cargo la ejecución de las estelas para dos reyes: Wepwawemsaf y Pantjeny, es decir los dos gobernantes que acompañarían a Senaaib en la dinastía de Abidos según Ryholt. En segundo lugar, este también fue el taller seguramente encargado de la producción de la estela de Rahotep datada en la dinastía XVII (Ilin-Tomich, 2012). En consecuencia, Marée propone que sería ilógico pensar que un mismo taller esté produciendo estelas para dos dinastías enemigas, a pesar que hay dudas sobre su datación y si alguna vez estas dos coexistieron o, como sostiene Ryholt (1997), se encuentran separadas por unos veinte años.

Julien Siesse (2015) cuestiona el orden de sucesión de los aproximadamente veinte gobernantes que tradicionalmente fueron asignados para finales de la dinastía XIII, la dinastía XVI o los comienzos de la dinastía XVII, a partir de un análisis del protocolo real y de la estructura del prenomen (nombre de trono) de cada rey. Según el autor los veinte o veintiún reyes tebanos o del sur de Egipto y los veintiséis que comúnmente se establecen a finales de la dinastía XIII, dinastía XVI o dinastía XVII comparten el nombre de trono basado en el modelo "Sekhemra-x-x" $(s h m-r c-h-h)$, elaborado durante la temprana dinastía XIII. Uno de los subtipos, "Sekhemra-verbo-khaw ( $s h m-r^{r}$-verbo$h^{\complement}(w)$, en el que se divide este modelo fue elegido por el grupo de tres reyes que Marée (2010) data alrededor de finales de la dinastía XVI o la temprana dinastía XVII. Estos reyes son: Rahotep (Sekhemra-Wahkhaw, shm-r ${ }^{-}-w 3 h-h^{\ulcorner} w$ ), Sobekemsaf I (Sekhemra-

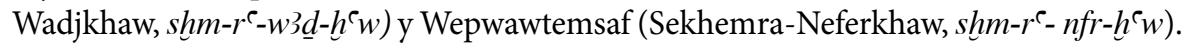
Sin embargo, para Ryholt (1997) serían los faraones que formaron parte de la dinastía de Abidos junto con Senaaib (Tabla 1).

El nombre de trono de Senaaib Menkhawra podría ser para Siesse una variante de este tercer subtipo, donde el elemento "sekhem" se pierde o se modifica. De todos modos, el estilo de la estela CG 20517 no se relaciona con el tipo de producción del taller identificado por Marée (Siesse, 2015), por lo cual pierde conexión directa con la dinastía de Abidos propuesta por Ryholt (1997). Nebiryraw comparte el mismo nombre de Horus (Sewadtawy, swd $\underline{d}$ t $3 w y$ ), gobernante que se lo ubica tradicionalmente en la dinastía XVI. Esto le permite a Siesse proponer una temporalidad no coincidente, es decir una posible datación para el reinado de Senaaib entre la tardía dinastía XVI o la temprana dinastía XVII. En cambio, si bien Beckerath (1964) admite una datación de Senaaib para finales de la dinastía XIII, advierte que su nombre del trono no sigue el tipo utilizado por la dinastía XIII, aunque pero sí resulta comparable con la forma del prenomen $s h m-r^{c}-h-h^{\top} w$, que fue llevada por tres reyes, uno de los cuales 
probablemente pertenezca al final de la dinastía XIII y los otros dos a comienzos de la dinastía XVII.

\section{Representación del rey, la corona khepresh}

Según lo propuesto por Davies (1982), en algún momento de la dinastía XIII los faraones egipcios comenzaron a ser representados portando una corona ajustada sobre la cabeza, con un uraeus en su parte delantera, tocado conocido como casquetereal (cap-crown) o casco-real (royal cap). De todos modos, en su forma original la tapa-corona es mencionada en las fuentes como khepresh y, como tal, se la considera antecesora de la corona-azul típica del reinado de Hatshepsut y Tutmosis III y que luego tuvo una nueva aparición durante el periodo amarniano y ramésida.

En un estudio sobre el tipo de corona azul utilizada por la reina Nefertity, Ertman (1976) afirma que en la estela de Senaaib se encuentra la representación más antigua que se conoce de un faraón portando el casquete-real, datándola en la dinastía XIII. De todos modos, Davies (1982) rastrea a través de diversas fuentes las diferentes etapas de desarrollo de la corona previas al Reino Nuevo egipcio, donde la estela de Senaaib se pone en contexto con otras evidencias (Figura 3).

Davies considera la evidencia material y en orden cronológico de la mención y/o representación de la corona khepresh de los siguientes reyes de la dinastía XVIII: 1) Sekhereahutawy Ammenemes Sobkhotep II, un relieve en piedra caliza del templo de Medamud; 2) Khanedrerre' Sokhotep IV, una estela de esquisto de dos caras proveniente del Wadi Hammamat; 3) Menkhaure' Senaaib, estela de piedra caliza pintada hallada en Abidos; 4) Sesostris I, estela de punta redondeada de arenisca del Templo Norte en Buhen y el grafito del templo en Medamud de un rey anónimo. Si bien este conjunto de piezas posee sus particularidades y variaciones, consideradas en conjunto adquieren un significado de interés al dar cuenta del origen de la corona khepresh. La estela de Senaaib, junto con la de Sobekhotep II, son las únicas que presentan los detalles del calado interno en el dibujo de las coronas y, juntamente con la de Sesostris I, son las únicas pintadas de color amarillo, color que se convertiría en la típica representación de la cap-crown en época ramésida. Es decir, que el trabajo que realiza Davies (1982) acerca una datación de la estela (según las características de representación de la corona del rey Senaaib) a la propuesta realizada por Beckerath (1964) (Figura 4).

El uso de la corona khepresh por parte de los reyes pudo haber tenido dentro de sus orígenes un significado ritual, pues es utilizada en un contexto de adoración y alabanza a los dioses. En su forma posterior de corona-azul quizá cumplió una función como símbolo de coronación, ya que tuvo su aparición en el contexto del Segundo Periodo Intermedio, época de gran inestabilidad política (Davies, 1982). La simbología en el uso de la corona puede explicar la representación del rey Senaaib como un acto de acción votiva y ritual al dios Min-Horus-nakht, o bien como reafirmaciónde su condición legítima de rey en Egipto.

Como ya se ha mencionado, Mariette en Catalogue général propuso tres agrupamientos de estelas de Abidos tomando como prototipo la de Senaaib, lo que esclarecería su contemporaneidad con la dinastía XIV. La segunda de estas subdivisiones se basaba en un estilo particular de representaciones: hombres con cabezas pequeñas, con el simple uso de un casco ajustado en la cabeza y el shenti con rayas profundas. Claramente, a lo que Mariette está haciendo referencia en la estela de Senaaib es a la cup-crown (el casco ajustado con ureus), pero sin poder identificarla como corona. De hecho, ninguna de las estelas de Abidos que el investigador pone en correlación son estelas reales, por lo cual el casco ajustado en la cabeza tendría otras connotaciones estilísticas no referidas al origen de la corona khepresh. 


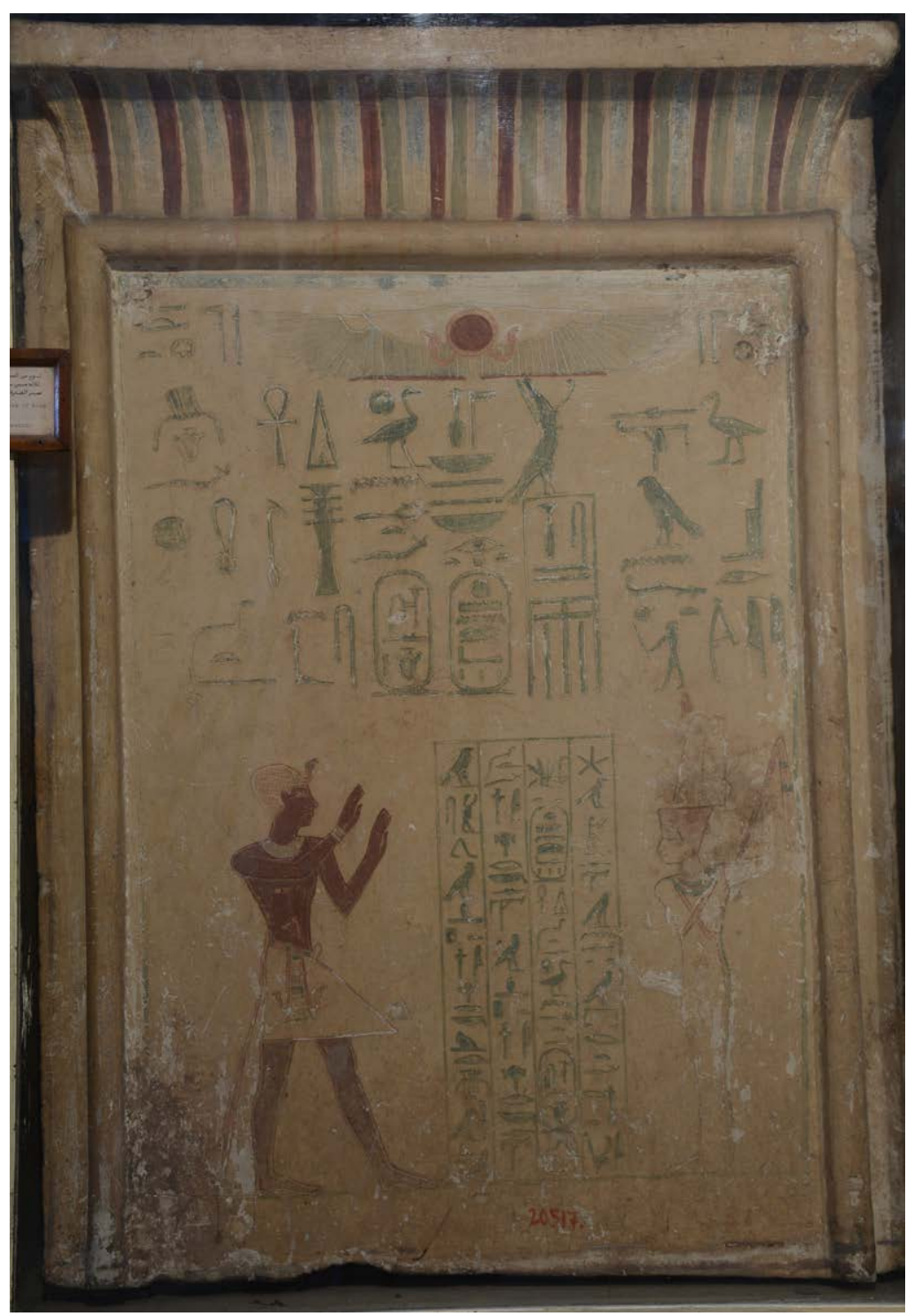

Figura 3. Foto de la estela CG 2017 ๑Museo Egipcio de El Cairo.

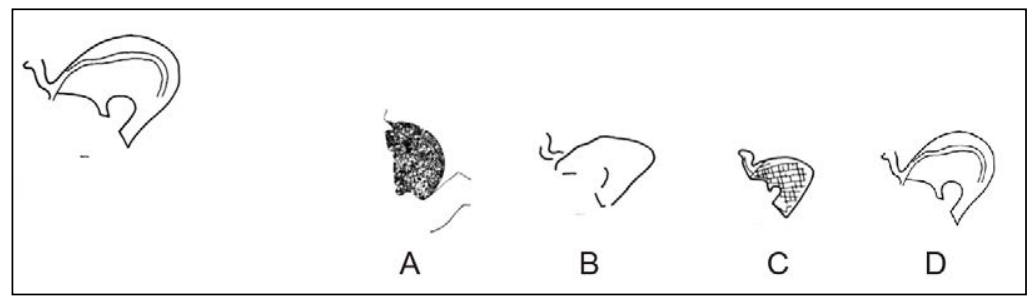

Figura 4. Esquema de coronas. Dibujos tomados de Davies (1984). A) corona de Sekhereahutawy Ammenemes Sobkhotep II; B) corona de Khanedrerre' Sokhotep IV; C) corona de Senaaib; $D$ ) corona de Sesostris I.

Mariette (1880) argumenta que la estela CG 20392 (= M 792), dedicada a un individuo llamado Sobkhotep, quien fuera administrador de las ofrendas divinas, se relaciona con la estela CG 20517 por tener ambos personajes masculinos la gorra ajustada en la cabeza. En un trabajo sobre la presencia de levantinos en Abidos durante la dinastía XIII y el temprano Segundo Periodo Intermedio, Mourad (2013) data la estela CG 
20392 entre las dinastías XII y XIII, por lo que si aceptamos la correlación estilística, correspondería a un período más temprano que el propuesto por Ryholt y por Siesse, acercándose nuevamente el estilo de representación de la corona del rey a la datación propuesta por Beckerath (1964).

\section{Sobre el himno de adoración al dios Min y la participación de Senaaib en el culto osiríaco en Abidos}

En el año 1928 el egiptólogo egipcio Hassan Sélim publica Hymnes religieux du Moyen Empire, obra en la que traduce y comenta tres estelas y un fragmento de estatua que contienen himnos de adoración al dios Min; estos son: la estela C30 del Museo del Louvre; las estelas CG 20089 y CG 20703 en el Grand Egyptian Museum y el fragmento de estatua 40959 del Museo Británico. En respuesta a este trabajo, Henri Gauthier publica un breve artículo "À propos des Hymnes adressés au dieu Min" (1939) dando cuenta de la omisión por parte de Hassan de cuatro himnos del Reino Medio dedicados al dios Min.

Según Gauthier (1930) esta incorporación completaría hasta ese momento un total de siete himnos conocidos dedicados a Min entre las dinastías XI a XVII, proponiendo una numeración del 1 al 7: los tres primeros conocidos por el trabajo de Hassan y los cuatro que él incorpora. El sexto himno es el que se corresponde con la estela CG 20517 que Gauthier titula como "Hymne à Min-Hor-Nakht"; está publicada una versión jeroglífica de la estela en la obra de Helck (1983). El autor lo atribuye al rey Senaaib - sólo transcribe en jeroglíficos su prenomen y su nombre como hijo de Ra, no así su nombre de Horus, que sí está escrito en la estela - con una datación amplia para el Segundo Periodo Intermedio. Gauthier (1930) realiza una copia de los jeroglíficos y una traducción casi completa del himno de adoración al dios Min, omitiendo la parte citada del protocolo real.

El contenido textual principal de la estela es un himno de adoración al dios Min, tradicionalmente asociado con la fertilidad en tanto regenerador de la vida y en su función de protector del desierto Oriental y de los expedicionarios hacia las tierras del Punt ${ }^{8}$. Sin embargo, la estela que el rey Senaaib dedica a Min - junto con otras estelas votivas que fueron dedicadas al dios- posiciona a esta divinidad en el contexto del culto osiríaco en Abidos, lo que resulta de una importancia cultural y religiosa singular. Un estudio reciente realizado por Olette-Pelletier (2018) evidencia que en el contexto abideano el dios Min es integrado al culto osiríaco con la creación del teónimo Min-Horus-nakht (Mnwhrw nht $)$, representando una nueva faceta divina para el Reino Medio y el Segundo Periodo Intermedio: lo convierte en el hijo de Osiris y por ende se integra en el linaje real definiéndose como una divinidad exclusivamente dinástica.

Por lo tanto, la estela de adoración de Senaaib al dios se pone en correlación con otras que también sintetizan la idea de que el dios Min-Horus-nakht fue la principal deidad en Abidos a comienzos del Segundo Periodo Intermedio9. La monarquía, es decir el soberano reinante, se expresa mediante la adoración a este dios sincrético como reflejo de sus propias características en su aspecto más bélico, el de Horus victorioso, autoridad que derrota al enemigo y, por ende, conservador de Maat. Estos aspectos se sintetizan en los símbolos del flagelo sostenido por su brazo levantado y la corona-shuty con dos altas plumas, característica del dios Osiris (Olette-Pelletier, 2018).

Las interpretaciones derivadas de la figura del dios Min-Horus-nakht plantean nuevos interrogantes en los estudios de la estela. Por un lado, el porqué de la elección de la
8. En relación al dios Min y el desarrollo de su culto algunas obras de referencia son: Gauthier (1930; 1931); McFarlane (1995), Olette-Pelletier $(2014 ; 2018)$ y Wainwright (1931).
9. Algunas de estas estelas fueron encontradas por Mariette: CG 20146, CG 20188, CG 20601, CG 20612, CG 20089, CG 20240, CG 20703; EA 506 (Simpson, 1974; Marée, 2013); Berlín 7287 (ÄIB I-II 1913-1924; Kaiser, 1967); estela real de Sobekhotep II (Delange, 1987; Gayet, 1889; Ledrain, 1879-1881; Pierret, 1874-1878), estela C30 de Sobek-iry (Lichtheim, 1973. publica ambos textos, el texto a Min se identifica con la estela en piedra de Mentuhotep IV en el Wadi Hammamat, Pierret, 18741878 y Gayet 1889), y $\mathrm{C}_{45}$ (OlettePelletier, 2014); las del Museo Cívico de Bologna publicadas por Bresciani (1985). 
figura de este dios por parte de un rey efímero, como lo fue Senaaib. Seguramente Senaaib intentaba de esa manera legitimar su reinado o quería reafirmar su propia condición de rey. La legitimación real en la región de Abidos tuvo durante el Segundo Periodo Intermedio en la figura de Min-Horus-nakht un símbolo representativo de su poder; por ello, la estela de Senaaib también es una estela de legitimación real, ya sea por la pérdida del poder político que estaban sufriendo los últimos gobernantes de la dinastía XIII o de fines de la dinastía XVII o por la justificación de una nueva línea dinástica en Abidos. En este sentido, no es casual que la representación de la figura humana del rey destaque su carácter guerrero con el uso del casco-corona, lo que está en consonancia con la figura de Min-Horus-nakht. Esta divinidad se revela como un dios guerrero, un Horus victorioso, para destacar sus atribuciones monárquicas (Olette-Pelletier, 2018). Es decir, entre la figura de Senaaib y la de la divinidad hay una retroalimentación simbólica para destacar el carácter monárquico.

Asimismo, hay que considerar el mensaje de la estela CG 20517 en relación con el espacio cultural y religioso involucrado por su emplazamiento en el recinto norte de Kom es-Sultan. La peregrinación anual a Abidos por parte de la realeza y la élite política y religiosa egipcia constituyó un hecho de importancia, no sólo para la conmemoración y recreación de la muerte y renacimiento de Osiris (Yoyotte, 1960), sino también porque las estelas poseían la intención de coparticipar eternamente a sus destinatarios en los beneficios de la celebración (Lavier, 1989). Así, Senaaib con su estela es partícipe de la memoria cultural (Assmann, 2005) construida alrededor del culto osiríaco en Abidos desde el Reino Medio y durante el Segundo Periodo Intermedio. Esto significa que Senaaib con su estela no solamente indica su interacción política y la afirmación de su posición como rey legítimo y garante del orden (Olette-Pelletier, 2018); además remite a su involucramiento en el continuum cultual y religioso abideano. Esta pertenencia cultural y política la reafirma en la explicitación de su relación como hijo de Osiris ( $M n w$ $h r(w) n h t ~ s 3$ Wsir mry, "Min-Horus-nakht, hijo de Osiris, su amado") y la evocación de la figura de Osiris-Khentiamentiu ind $h r . k$ Wir hnty-imn tw $m$ htp, "Saludo a ti Osiris-Khentiamentiu, está en paz"), las principales figuras divinas adoradas en Abidos y que hicieron de éste uno de los principales centros religioso del antiguo Egipto (Smith, 2017; Snape, 2011).

\section{Transliteración y traducción de la estela CG 20517}

\section{Primer registro (sección A)}

Bhdty ntr $3 /$ Bhdty ntrr 3

El Behedita, dios grande / el Behedita, dios grande

\section{Segundo registro (sección B)}

10. Sobre la lectura y traducción del nombre del dios teónimo se han realizado diferentes propuestas: "Min-Horus victorioso" (Hassan, 1928); "Min-Horus el poderoso" (Leitz, 2002); en tanto sincretismo entre Min-Horus (Forgeau, 2010); "Min-Horus el fuerte" (Bresciani, 1979; 2003); "Min-Horus nakht" como una divinidad monárquica (Olette-Pelletier, 2018).

11. Al respecto véase Routledge (2007).
Mnw hr(w) nht s3 Wsir mry

Min-Horus-nakht ${ }^{10}$, hijo de Osiris, (su) amado

$h r(w)$ swd $t 3 w y$ ntr $n f r n b t 3 w y$ nb irt-h $h t^{11}$

Horus Sewadjtawy, dios bueno, señor de las Dos Tierras, señor de las ejecuciones rituales

s3 $r^{\odot} n \underline{h}$ tf $s n^{c e i b}$

Hijo de Ra, de su cuerpo, Senaaib

di `nh $\underline{d} d$ w3s snb $3 w$ ib.f mi $r^{\ulcorner} \underline{d} t$ a quien es dada vida, estabilidad, dominio y salud, el está jubiloso como Ra, eternamente. 


\section{Himno de adoración al dios Min-Horus nakht (sección C)}

dw3 Mnw hr(w) nht m prt nfr.t in sw-bit Mnh" ${ }^{\top} r^{\top}$

Adoración a Min-Horus-nakht en su bella procesión, por el rey del Alto y Bajo Egipto

Menkhaura,

$\underline{d i} \Gamma^{\Gamma} h \underline{d} \underline{d} t$

a quien es dada vida eternamente.

$s^{3} r^{\ulcorner} n \underline{h} t . f s n^{e c i b} n h \underline{h} \underline{d} t$

Hijo de Ra de su cuerpo, Senaaib, (pueda él) vivir eternamente.

dd.f ind hr. $k$ Mnw $m$ htp

Él dice: "Saludo a tí Min, está en paz.

ind hr. $k$ Mnw hrw šms $m$ ḥtp

Saludo a ti Min-Horus, jacompaña en paz!

ind $\underline{h} r . k$ Wir hnty-imn tw $m$ htp

Saludo a ti Osiris-Khentiamentiu, está en paz".

\section{Conclusión}

La datación de la estela CG 20517 y del reinado de su propietario, el rey Senaaib, se presenta como uno de los problemas dentro de la cronología dinástica del Egipto faraónico y particularmente del Segundo Periodo Intermedio, del que todavía no se han logrado consensos entre los especialistas. Esta controversia es el resultado de interpretaciones dispares basadas en argumentos construidos desde diferentes posicionamientos teóricos, metodológicos y fuentes analizadas. Es decir, las distintas propuestas para el estudio de la estela CG 20517 -muchas de las cuales son contrapuestas - se han detenido a analizar sólo alguno de los aspectos derivados de ella, ya sea interpretando su funcionalidad, contenido textual, formas de representación o posible mención del rey Senaaib en fuentes posteriores.

De este modo, parafraseando a Detlef Franke (2013), las preguntas correctas permitirán responder y comprender los códigos culturales involucrados en las estelas. Consideramos que estas indagaciones deben partir de una mirada conjunta de todos los aspectos involucrados en el objeto, haciendo evidente las contradicciones en el análisis para la construcción de posibles nuevos argumentos y la propuesta de nuevas líneas de análisis.

Por esta razón a lo largo del trabajo se han expuesto diferentes interpretaciones que permiten resituar la estela y la actuación de su propietario en el contexto cultural y religioso del Segundo Periodo Intermedio en Abidos. Sin embargo, como hemos visto, los planteaos de algunos autores desestiman una posible lectura del nombre de Senaaib en la Lista Real de Abidos y por consiguiente, una datación en la dinastía XIV como la había realizado originariamente Mariette. De este modo, se abre un abanico de posibilidades de datación de la estela y el reinado de Senaaib, que van desde el último cuarto de la dinastía XIII, la pertenencia a una dinastía de Abidos o fecharla a finales de la dinastía XVI o comienzos de la dinastía XVII. Cabe destacar que asumir cualquiera de ellas sería un riesgo ya que en el futuro podrían encontrarse nuevas evidencias que confirmen alguna de estas propuestas.

Asimismo, consideramos que es fundamental en el análisis tener en cuenta la textualidad y espacialidad de la estela de Senaaib. Su emplazamiento en el área de Kom el-Sultan 
en Abidos, su contenido textual (el himno al dios Min-Horus-nakht), el nombre del trono de rey y su característica representación como faraón guerrero permiten asumir en conjunto que Senaaib reconocía los mecanismos que daban legitimidad a la realeza, incluyendo su nombre y la evocación de símbolos míticos-religiosos que lo hicieran partícipe y reproductor del culto osiriáco abideano en algún momento del Segundo Periodo Intermedio.

\section{Agradecimientos}

Este trabajo forma parte del proyecto de investigación dirigido por la Dra. Andrea P. Zingarelli, "Estudios sobre las elites en Abidos a partir de las estelas del Museo de El Cairo" radicado en la Universidad Nacional de La Plata (Argentina). Agradezco a las autoridades del Museo de Antigüedades Egipcias de El Cairo por permitir la publicación de la estela CG 20517, especialmente a Marwa Bdr El Din, jefa del Departamento de Documentación y de Gestión del Registro de Colecciones, y a mi compañero y colega Dr. Pablo Martín Rosell por las gestiones realizadas en el Museo en enero de 2018. También a la Dra. Eva Amanda Calomino por la dedicación en el dibujo de la estela; los errores que se desprendan de su interpretación quedan bajo mi responsabilidad. Asimismo hago extensivo mi agradecimiento a quienes fueron evaluadores de este trabajo, por su tiempo y comentarios realizados. 


\section{Referencias citadas}

》 ÄlB. (1913-1924). Ägyptische Inschrifenaud den königlichen Museen zu Berlin I-II. Leipzig: Hinrichs.

" Assmann, J. (2005). Das kulturelle Gedächtnis: Schrift, Erinnerung und politische Identität in frühen Hochkulturen. Berlín: C.H. Beck

» Beckerath, J. (1964). Untersuchungen zur politischen Geschichte der Zweiten Zwischenzeit in Ägypten. Glückstadt: J.J. Augustin.

"Bresciani, E. (1979). Un edificio di Kha-anekh-Ra Sobek- hotep ad Abido. Egitto e Vicino Oriente, 2, 1-20.

» Bresciani, E. (1985). Le steleegiziane del Museo cívico archeologico di Bologna. Italia: Longo Editore Ravenna.

》 Bresciani, E. (2003). Scrittiscelti di Edda Bresciani in Egitto. Egitto e Vicino Oriente, número especial, 1-234.

" Cervelló Autori, J. (2009). La aparición del Estado y la Época Tinita. En J. M. Parra (Ed.), El Antiguo Egipto (pp. 69-124). Madrid: Marcial Pons.

"Davies, W. V. (1982). The Origin of the Blue Crown. Journal of Egyptian Archaeology, 68, 69-76.

》Delange, E. (1987). Catalogue des statues égyptiennes du Moyen Empire, 2060-1560 avant J.C. París: Broché.

»Dreyer, G. (1990). Umm el-Qaab. Nachuntersuchungen im frühzeitlichen Königsfriedhof, 3/4. MDAIK, 46, 53-90.

»Dreyer, G. (1998). Umm el-Qaab I. Das prädynastische Königsgrab U-j und seine frühen Schriftzeugnisse. Archäologische Veröffent-lichungen 86: Philipp von Zabern, Mainz am Rhein.

" Dreyer, G., Effland, A., Effland, U., Engel, E.-M., Hartmann, R., Hartung, U., Lacher, C., Müller, V. y Pokorny, A. (2006). Umm el-Qaab, Nachuntersuchungen im frühzeit lichen Königs friedhof, 16./17./18. MDAIK, 62, 11-81.

》Ertman, E. (1976). The Cap-Crown of Nefertiti: Its Function and Probable Origin. Journal of the American Research Center in Egypt, 13, 63-67.

" Franke, D. (1988). Zur Chronologie des Mittleren Reiches. Teil II: Die sogenannte Zweite Zwischenzeit Altägyptens. Orientalia, 57, 113-138.

» Franke, D. (2013). Introduction. En M. Marée (Ed.), Egyptian Stelae in the British Museum from the 13th-17th Dynasties (Volumen 1, pp. 1-22). Londres: British Museum.

»Forgeau, A. (2010). Horus-fils-d'Isis, la jeunesse d'un dieu. El Cairo: BdE 150.

»Gardiner, A. (1959). Royal Canon of Turin. Oxford: Griffith Institute.

» Gauthier, H. M. (1930). À propos des Hymnes adressés au dieu Min. Bulletin de l'Institut Français d'Archéologie Orientale, 30, 553-564.

"Gauthier, H. (1931). Las fêtes du dieu Min. El Cairo: Bulletin de l'Institut Français d'Archéologie Orientale.

》 Gayet, A. J. (1889). Musée du Louvre. Stèles de la Xlle dynastie. París: F. Vieweg, LibraireÉditeur. 
» Gehrden, K. M. (1986). Stele. En W. Helck y E. Otto (Eds.), Lexicon der Ägyptologie. Band $\mathrm{VI}$ (pp. 1-6). Wiesbaden: Harrassowitz.

» Grajetzki, W. (2006). The Middle Kingdom of Ancient Egypt. Londres: Duckworth.

» Hassan, S. (1928). Hymnes religieux du Moyen Empire. El Cairo: Bulletin de I'Institut Français d'Archéologie Orientale.

» Helck, W. (1956). Untersuchungen zu Manetho und den ägyptischen Königlisten. Berlín: UGAÄ.

» Helck, W. (1983). Historisch-Biographische Texte der 2. Zwischen zeit und Neue Texte der 18. Dynastie. Wiesbaden: Otto Harrassowitz.

" Ilin-Tomich, A. (2012). Late Middle Kingdom Stelae Workshops. Göttinger Miszellen: Beiträge zur ägyptologischen Diskussion, 234, 69-84.

» Jiménez Fernández, J. y Jiménez Serrano, A. (2008). Historia de Egipto, Manetón. Madrid: Akal.

》 Kaiser, W. (Ed.). (1967). Ägyptisches Museum Berlin. Berlín: Hartmann.

»Lange, H. O. y Schäfer, H. (1902-1925). Grab- und Denksteine des Mittleren Reichsim Museum von Kairo. Vol. I-IV. Berlín: Reichsdruckerei.

" Lavier, M-C. (1989). Les Mystères d'Osiris à Abydos d'après les stlèles du Moyen Empire et du Nouvel Empire. SAK, 3, 289-295.

"Leahy, A. (1989). A protective Measure at Abydos in the Thirteenth Dynasty. Journal of Egyptian Archaeology, 75, 41-60.

» Lebée, T. (2013). Le musée d'antiquités égyptiennes de Būlāq (1858-1889). Faire connaître et aimer l'Égypte ancienne au XIX siècle. París: École du Louvre, Mémorie d'étude.

»Leclant, J. (1981). Mariette Pacha et le patrimonie archéologique de l'Égypte. Comptes rendus des séances de l'Académie des Inscriptions et Belles-Lettres, 125, 487-496.

》 Ledrain, E. (1879-1881). Les monuments égyptiens de la Bibliothèque nationale (Cabinet des médailles et antiques). París: R. Vieweg.

» Leitz, C. (2002). Lexicon der ägyptischen Götter und Götterbezeichnungen (Vol. VIII). París: OLA, Peeters.

"Leprohon, R. L. (2013). The Great Name: Ancient Egyptian Royal Titulary. Atlanta: Society of Biblical Literature.

» Lichtheim, M. (1973). Ancient Egyptian Literature: Volume I: The Old and Middle Kingdoms. California: University of California Press.

" Malek, J. (1982). The Original Version of the Royal Canon of Turin. The Journal of Egyptian Archaeology, 68, 93-106.

" Marée, M. (2010). A sculpture workshop at Abydos from the late Sixteenth or early Seventeenth Dynasty. En M. Marée, (Ed.), The Second Intermediate Period (ThirteenthSeventeenth Dynasties): Current Research, Future Prospects (pp. 241-282). Leuven: Peeters

"Marée, M. (Ed.). (2013). Egyptian Stelae in the British Museum from the 13th to 17th Dynasties. Londres: The British Museum.

"Mariette, F. A. F. (1880). Catalogue general des monuments d'Abydos découvets pendant les foulles de cetteville. París: Imprimerie Nationale.

» McFarlane, A. (1995). The God Min to the End of the Old Kingdom. Australia: Australian Center for Egyptology. 
" Meyer, E. (1904). Aegyptische Chronologie. Berlín: Der Königl Akademie der Wissenschaptien.

" Mourad, A. (2013). Asiatics and Abydos: From the Twelfth Dynasty to the Early Second Intermediate Period. The Bulletin of the Australian Centre for Egyptology, 24, 31-58.

"O'Connor, D. (2009). Abydos. Egypt's First Pharaohs and the Cult of Osiris. Londres: Thames \& Hudson.

" Olette-Pelletier, J-G. (2014). Le Dieu Min "Protecteur de la Lune". Aspects et rôles lunaires du dieu de la fertilité. Egypte, Afrique \& Orient, 72(2), 9-16.

»Olette-Pelletier, J-G. (2018). Le dieu Min au Moyen Empire: dieu monarchique, die de l'elite. En Actas del Coloquio “Le sacré dans tous ses états” (pp. 20-31). París: UQAM.

»Petrie, W. M. F. (1900-1901). The royal tombs of the first dynasty. Londres y Boston: Egypt Exploration Fund.

» Pierret, P. (1874-1878). Recueil d'inscriptions inédites du musée égyptien du Louvre I-II. París: G. Olms.

"Redford, D. B. (1986). Pharaonic King-List, Annals and Day-Books. A Contribution to the Study of the Egyptian Sense of History. Mississauga: SSEA.

" Reid, D. (2002). Whose Pharaohs? Archeology, Museums, and Egyptian National Identity from Napoleon to World War I. El Cairo: The American University in Cairo Press.

" Richards, J. (2005). Society and Death in Ancient Egypt. Mortuary Landscapes of the Middle Kingdom. Nueva York: Cambridge University Press.

» Rosell, P. M. (2018). Deseos para la eternidad. La fórmula de Abidos y el desarrollo de los misterios de Osiris en las estelas votivas del Reino Medio egipcio. Hélade, 4(2), 43-61.

» Routledge, C. (2007). The Royal Title nbirt-ht. Journal of American Research Center in Egypt, 42, 193-220.

» Ryholt, K. (1997). The Political Situation in Egypt during the Second Intermediate Period, 1800-1550 BC. Copenhague: CNI.

» Ryholt, K. (2004). The Turin King-list. Ägypten und Levante, 14, 135-155.

" Ryholt, K. (2006). The Turin King-list or so-called Turin Canon (TC) as a source for Chronology. En E. Hornung, R. Krauss y D. A. Warburton (Eds.), Ancient Egyptian Chronology (pp. 26-32). Leiden y Boston: Brill.

» Salem, L. y Calomino, E. (en prensa) Categorías difusas: hacia una reconceptualización de las estelas de Abidos. Revista Mundo de Antes.

"Schäffer, H. (1904). Die Mysterien des Osiris in Abydos unter König Sesostris III. Nach dem Denkstein des ober schatzmeisters I-cher-nofret in Berliner Museum. Leipzig: Hinrichs.

"Seidlmayer, S. J. (2007). El origen del Estado en el antiguo Egipto. Boletín de Arqueología de la Pontificia Universidad Católica del Perú, 11, 325-351.

"Sélim, H. (1928). Hymnes religieux du Moyen Empire. El Cairo: Service des Antiqués de l'Égypte.

"Siesse, J. (2015). Throne Names as a Clue for the Internal Chronology of the 13th to 17th Dynasties (Late Middle Kingdom and Second Intermediate Period). GM, 246, 75-98.

" Simpson, K. (1974). The Terrace of the Great God at Abydos: The Offering Chapels of Dynasties 12 and 13. New Heaven: Peabody Museum of Natural History of Yale University.

»Smith, M. (2017). Following Osiris. Perspectives on the Osirian Afterlife from Four Millennia. Oxford: Oxford University Press. 
"Snape, S. (2011). Ancient Egyptian Tombs: The Culture of Life and Death. Londres: John Wiley \& Sons.

"Van Wetering, J. (2004) The Royal Cemetery of the Early Dynastic Period at Saqqara and the Second Dynasty Royal Tombs. En S. Hendrickx, R. F. Friedman, K. M. Cialowicz y M. Chlodnicki (Eds.), Egypt at its Origins. Studies in Memory of Barbara Adams (pp. 10551080). Leuven: Peeters.

"Waddell. W.G. (1940). Manetho. Edimburgo: Loeb.

»Wainwright, G. A. (1931). The Emblem of Min. Journal of Egyptian Archaeology, 17, 185-195.

"Wegner, J. (2015). A Royal Necropolis at South Abydos: New Light on Egypt's Second Intermediate Period. Near Eastern Archaeology, 78(2), 68-78.

"Yamamoto, K. (2015a). Abydos and Osiris. The Terrace of the Great God. En A. Oppenheim, D. Arnold y K. Yamamoto (Eds), Ancient Egypt Transformed: The Middle Kingdom (pp. 250-269). Nueva York: Metropolitan Museum of Art.

"Yamamoto, K. (2015b). The Art of the Stela. An Appeal to the Living. En A. Oppenheim, D. Arnold y K. Yamamoto. (Eds.), Ancient Egypt Transformed: The Middle Kingdom (pp. 33-36). Nueva York: Metropolitan Museum of Art.

» Yoyotte, J. (1960). Les pèlerinages dans I'Égypt eancienne. En J. Yoyotte (Ed.), Les Pèlerinages (pp. 19-74). París: Seuil. 